\title{
Função perda de Taguchi aplicada na criação de tilápia, Oreochromis niloticus alimentadas com diferentes inclusões de levedura na ração
}

\section{Taguchi loss function applied in the tilapia, Oreochromis niloticus fed with different additions of yeast in the diet}

\author{
Vandir Medri ${ }^{1 *}$; Waldir Medri ${ }^{2}$; Mauro Caetano-Filho ${ }^{3}$
}

Resumo

Foram utilizados 72 juvenis de tilápia do Nilo, Oreochromis niloticus, sexualmente revertidos, com peso médio inicial de $37,27 \pm 4,92 \mathrm{~g}$, distribuídos num delineamento inteiramente casualizado, durante 112 dias. Este trabalho avaliou o efeito da introdução de gaiolas com cultivo de tilápias alimentados com $0 \%$ (controle), $20 \%, 40 \%$ e $60 \%$ (grupos teste) de levedura em substituição à ração de fontes tradicionais sobre o peso, a sobrevivência e conversão alimentar e também verificou se há diferença entre a função perda de Taguchi para a produção total, para os peixes mortos e descartados e as quatro rações balanceadas. A análise de variância foi aplicada mostrando que não houve diferenças estatísticas $(p>0,05)$ entre os efeitos dos tratamentos sobre a sobrevivência e conversão alimentar, mas houve efeito quadrático sobre o ganho de peso das tilápias $\left(\mathrm{Y}=73,39+0.173 \mathrm{X}-0.0034 \mathrm{X} 2 ; \mathrm{R}^{2}=0,9986\right)$, concluindo que o melhor nível de inclusão de levedura como fonte protéica na dieta para juvenis revertidos é de $25,44 \%$. As perdas de Taguchi para os custos de produção e para os peixes mortos nos tratamentos $\mathrm{T}_{2}=$ $20 \%, \mathrm{~T}_{3}=40 \%$ e $\mathrm{T}_{4}=60 \%$ foram menores que o grupo controle $\left(\mathrm{T}_{1}=0 \%\right)$. Este resultado confirma o direcionamento da inclusão de levedura de destilaria em substituição a ração de origem tradicional.

Palavras-chave: Estatística, sobrevivência, tratamento, variância

\begin{abstract}
The experiment was based on observations of 72 juveniles of tilapias of Nile, Oreochromis niloticus, sexually reverted, with an initial medium weight of $37.27 \pm 4.92 \mathrm{~g}$, distributed in a completely randomized design for 112 days. This work has evaluated the effect of the introduction of cages with cultivation of tilapia fed $0 \%$ (control), $20 \%, 40 \%$ and $60 \%$ (groups test) of yeast replacing the traditional sources of diet on weight, survival and feed conversion and also there is no difference between the loss function of Taguchi to the total for the dead fish and discarded and the four balanced rations. The analysis of variance was applied showing that there were no statistical differences $(p>0.05)$ between the effects of treatments on the survival and feed conversion, but there was a quadratic effect on weight gain of tilapia $(\mathrm{Y}=73.39+0.173 \mathrm{X}-0.0034 \mathrm{X} 2, \mathrm{R} 2=0.9986)$, concluding that the best level of inclusion of yeast as protein source for juvenile is reversed $25.44 \%$. Taguchi's loss for the cost of production and for the dead fishes in the treatment $\mathrm{T}_{2}=20 \%, \mathrm{~T}_{3}=40 \%$ and $\mathrm{T}_{4}=60 \%$ were lower the group control $\left(\mathrm{T}_{1}=0 \%\right)$. This result confirms the direction of inclusion of distillers yeast in place of traditional feed source.
\end{abstract}

Key words: Statistics, survival, treatment, variance

\footnotetext{
1 Doutor em Engenharia de Produção pela Universidade Federal de Santa Catarina (UFSC); Professor Associado do Departamento de Estatística, Universidade Estadual de Londrina/Pr. E-mail: vandir@uel.br.

2 Doutor em Engenharia de Produção pela Universidade Federal de Santa Catarina (UFSC); Professor Associado do Departamento de Estatística, Universidade Estadual de Londrina/Pr. E-mail: medri@uel.br.

3 Docente do Departamento de Biologia Animal e Vegetal - CCB/BAV. E-mail: mauro@uel.br.

* Autor para correspondência
} 


\section{Introdução}

A tilápia do Nilo destaca-se como peixe de potencial para aqüicultura, visto a sua rusticidade, crescimento rápido e adaptação ao confinamento (HAYASHI, 1995, MACINTOSCH; LITTLE, 1995); possui hábito alimentar onívoro, e aceita rações com grande facilidade, desde o período de pós-larva até a fase de terminação. De acordo com Popma e Phelps (1998), a tilápia é, entre as espécies de peixes mais cultivadas, a que melhor resiste à alta temperatura, a baixa concentração de oxigênio dissolvido e a alta concentração de amônia na água. Já Lahav e Ra'nam (1997) citam que a principal vantagem da tilápia do Nilo é o seu baixo custo relativo, principalmente quanto ao alevino, à alimentação e à qualidade da sua carne. Outro fator importante é a boa aceitação no mercado de lazer (pesque-pague) e de alimento (frigoríficos), pelas qualidades nutritivas e organolépticas do seu filé (BOSCOLO et al., 2001). A espécie de tilápia preferida para o cultivo é a $O$. niloticus, por causa do seu rápido crescimento e sua coloração clara (LOVSHIN, 1997).

A aqüicultura de tilápias tem crescido durante a década de 1990 e a previsão indica que a indústria continuará a expandir significativamente nos anos por vir (ALCESTE; JORY, 2002).

A tecnologia para a cultura de tilápia em gaiolas tem tornado o Brasil o maior produtor de tilápia em gaiolas da América Latina (BOZANO; ROMERO, 2001). Com a técnica de criação de tilápias em gaiolas, pode ser produzido um maior número de peixes por área. Essa técnica utiliza apenas peixes machos por apresentarem melhor desenvolvimento.

Rações de boa qualidade diminuem os problemas de poluição (CYRINO et al., 1998). No entanto, em regiões onde não há indústrias de rações estas chegam ao produtor a um custo muito elevado. $\mathrm{O}$ que onera ou inviabiliza a prática do cultivo. Assim sendo, identificar produtos alternativos ou mesmo formulações que diminuam os custos de produção de peixes e mantenham a qualidade da água nos níveis recomendada à criação, parece ser uma das alternativas para explorar de forma sustentável os recursos hídricos a produção de pescado.

Alguns autores destacaram que os ingredientes que compõem a dieta podem determinar sua ingestão ou rejeição e até a quantidade a ser consumida. Neste sentido, Pereira - da - Silva e Pezzato (2000), estudaram as respostas comportamentais da tilápia do Nilo frente a diferentes ingredientes comumente empregados na formulação das dietas, constatando que a levedura de cana-de-açúcar apresentou média atrato-palatabilidade.

A levedura é um produto valioso, com adequado balanceamento, retirado do processo de fermentação alcoólica, sendo uma importante alternativa protéica na formulação de rações animais, podendo alcançar altos níveis de proteínas, carboidratos, lipídios, extrato etéreo, vitaminas e minerais (MATTOS; DANTAS D`ARCE; MACHADO, 1984).

As tilápias apresentam habilidade em aproveitar resíduos da agropecuária como a levedura, além da possibilidade de assimilar eficientemente os carboidratos contidos nos ingredientes de origem vegetal das rações. Estes resíduos agropecuários podem ser aproveitados como suplemento em rações animais reduzindo os custos de produção, além de diminuir a poluição ambiental (LITCHFIELD, 1983; ALCOPAR, 1992).

No Brasil, há possibilidade para produção de leveduras ou grupos para consumo humano, ou animal. Em curto prazo, porém o uso animal é mais realista e já vem até ocorrendo. Serão necessários, porém daqui para frente mais trabalhos de avaliação nutricional e toxicológica, estabelecimento de técnicas e normas para tal, adequadas as nossas condições e produtos (ALVES et al., 1988).

Propõe-se a integração da piscicultura com a agricultura, com a indústria e com a pecuária, elas se necessitam, para que a economia de produção de alimentos consiga expandir. O Brasil poderá se transformar no maior e melhor celeiro do mundo. Um celeiro que terá no sistema aquícola a sua 
principal alavanca de produção de proteína animal a baixo custo.

\section{Perdas de Taguchi}

A função perda de Taguchi ou da qualidade é definida como o valor esperado da perda monetária causada por desvios da característica de desempenho em relação ao valor desejado ou especificado. Para Taguchi, Taguchi e Chowdhury (1999), a produção, o uso e o descarte de um produto sempre acarretam prejuízos (perdas) para a sociedade; quanto menor for o prejuízo, melhor será a qualidade do produto. Este conceito de perda mostra uma nova forma de pensar em investimentos na melhoria da qualidade, pois numa economia competitiva, a melhoria contínua da qualidade e redução do custo faz-se necessária para que o produto se mantenha no mercado (KACKAR, 1986). As perdas consideradas aqui são medidas em valor monetário e estão associadas a características quantificáveis do produto e não precisam ser exatas (DEMING, 1997).

Taguchi, Elsayed e Hsiang (1990), tem com hipótese, geralmente aceita, de que a distribuição probabilística dos valores obtidos na produção em grande escala é normal e não uniforme, isto é, segue a função reduzida de Gauss. Ele tem retratado a idéia de que a variação do alvo desejado acarreta perdas para a sociedade.

O mesmo autor toma como base da perda para a sociedade, a diferença entre o valor nominal $\mathrm{m}$ e o valor obtido $\mathrm{x}$, no caso simplificado de sua qualidade depender de uma única dimensão. No caso mais geral da qualidade depender de várias dimensões, aplica-se à função perda a cada dimensão e o valor da perda causada é a soma de todas essas perdas individuais. Em outras palavras, cada unidade causa uma perda, que se distribui entre a sociedade toda e não fica só para o seu proprietário (STANGE, 1996; MEDRI et al., 2004).

Foi desenvolvido o conceito de função perda de Taguchi que relaciona o valor monetário da perda da qualidade com o afastamento do valor nominal (m) da especificação. Mostrou que esta função é do tipo quadrático. Atinge um valor máximo quando o desvio excede os limites de especificação (TAGUCHI; ELSAYED; HSIANG, 1990; GUEDES, 1996).

Casos especiais de características funcionais da qualidade - Tipos de tolerâncias

Este item ilustra a avaliação do nível da qualidade dos produtos, utilizando o conceito da função perda para os seguintes tipos de tolerâncias:

\section{Nominal é Melhor (tipo N)}

Exige-se este tipo de tolerância para muitos produtos, peças, elementos e componentes quando se prefere um tamanho (ou característica) nominal.

\section{2. quanto Menor Melhor (tipo S)}

Envolve uma característica não-negativa, cujo valor ideal é zero. Um exemplo típico de tal característica é a impureza. Desgaste, encolhimento, deterioração e nível de perturbação são também bons exemplos deste tipo.

3. quanto Maior Melhor (tipo L).

É aplicável a características tais como a resistência dos materiais e o rendimento de combustíveis. Nestes casos, não há valores nominais pré-determinados e quanto maior for o valor da característica, melhor será a qualidade do produto (ROSS, 1991).

O objetivo deste trabalho é avaliar o efeito com cultivo de tilápias alimentados com $0 \%$ (controle), $20 \%, 40 \%$ e $60 \%$ (grupos teste) de levedura em substituição à ração de fontes tradicionais sobre a sobrevivência e conversão alimentar e também verificar se há diferença entre a função perda de Taguchi para a produção total, para os peixes mortos e descartados e as quatro rações balanceadas.

\section{Material e métodos}

O experimento foi realizado na Estação de Piscicultura da Universidade Estadual de Londrina 
(EPUEL), PR ( $23^{\circ} 30^{`} \mathrm{~S}$ e $\left.51^{\circ} \mathrm{W}\right)$, no período de 17 de maio a 6 de setembro de 2002.

Foram utilizados 72 juvenis de tilápia do Nilo com peso vivo médio de $37,27 \pm 4,92 \mathrm{~g}$. Os peixes foram revertidos através do fornecimento de ração com $60 \mathrm{mg} / \mathrm{kg}$ de dieta do hormônio masculinizante $17 \alpha$-metiltestosterona, utilizando a técnica descrita por Popma e Green (1990) durante um período de 28 dias. Foram elaborados quatro rações com níveis de 0; 20; 40 e 60\% de levedura em substituição à ração de fontes tradicionais. Foi utilizado um programa computacional para o balanceamento da ração com as necessidades da espécie em questão. (Tabela 1). A ração controle é a ração comercial habitualmente utilizada pela Estação de Piscicultura para a alimentação de peixes, sendo que as rações avaliadas atenderam as mesmas exigências nutricionais.

Os juvenis foram distribuídos aleatoriamente em 12 grupos de 6 indivíduos, cada grupo foi colocado em gaiola com capacidade de 100 litros, constante aeração e entrada de água. Foi abastecido com água do poço semi-artesiano com renovação de 50\%/ dia. O modelo experimental foi o delineamento inteiramente casualizado.

Tabela 1. Composição bromatológica e percentual das rações experimentais para tilápias do Nilo (com base na matéria seca).

\begin{tabular}{lcccc}
\hline & \multicolumn{4}{c}{ Níveis de inclusão de levedura (\%) } \\
\cline { 2 - 5 } Ingredientes (\%) & $\mathbf{0 , 0 0}$ & $\mathbf{2 0 , 0 0}$ & $\mathbf{4 0 , 0 0}$ & $\mathbf{6 0 , 0 0}$ \\
\hline Farinha de peixe & 10,00 & 10,00 & 10,00 & 5,00 \\
Farinha de trigo & 5,00 & 5,00 & 5,00 & 5,00 \\
Milho cozido & 44,35 & 35,36 & 25,14 & 11,76 \\
Farelo de soja & 38,65 & 26,64 & 14,86 & 10,00 \\
Fosfato bicálcico & 0,00 & 0,00 & 0,00 & 1,24 \\
Óleo vegetal $_{\text {Suplem. Mineral }}^{1}$ & 0,00 & 1,00 & 3,00 & 5,00 \\
Suplem. Vitamínico & 1,00 & 1,00 & 1,00 & 1,00 \\
\hline Total & 1,00 & 1,00 & 1,00 & 1,00 \\
\hline Composição & $\mathbf{1 0 0 , 0 0}$ & $\mathbf{1 0 0 , 0 0}$ & $\mathbf{1 0 0 , 0 0}$ & $\mathbf{1 0 0 , 0 0}$ \\
\hline Matéria seca (\%) & & & 89,72 & 90,37 \\
ED (kcal/kg) & 88,54 & 89,07 & 3065,53 \\
Gordura (\%) & 3136,30 & 3094,58 & 6,07 \\
Fibra bruta (\%) & 2,81 & 3,38 & 4,91 & 1,45 \\
Mt. Mineral (\%) & 3,96 & 3,01 & 2,04 & 8,86 \\
Fósforo total (\%) & 5,44 & 6,40 & 7,35 & 0,54 \\
Proteína bruta (\%) & 0,67 & 0,60 & 0,52 & 28,00 \\
Cálcio (\%) & 28,00 & 28,00 & 28,00 & 0,70 \\
\hline
\end{tabular}

${ }^{1}$ Níveis de garantia por kg Pirá tropical: Vit A, 12000 UI; Vit D, 2000 UI; Vit. E, 15 UI; Vit. K, 2,00 mg; Vit. B , 0,15 mg; Ácido Pantotênico, 11,00 mg; Tiamina, 1,50 mg; Colina, $350 \mathrm{mg}$; Niacina, $35 \mathrm{mg}$; Pirodoxina, 2,50 mg, Riboflavina, $600 \mathrm{mg}$; Ácido Fólico, 0,60 mg; Zinco, 60 mg; Biotina, 100 mg; Manganês, 70 mg; Cobre, 8,00 mg; Ferro, 30 mg; Iodo, 1,00 mg; Cobalto, 0,10 $\mathrm{mg}$; Selênio, 0,20 mg; Antioxidante, $125 \mathrm{mg}$.

Os peixes foram observados diariamente quanto à apresentação de comportamento incomum, variações morfológicas e mortalidade.

Cada ração foi fornecida na forma peletizada a três grupos de peixes (triplicata). Os juvenis foram alimentados duas vezes por dia, às $8 \mathrm{~h}$ e $17 \mathrm{~h}$ na proporção de $2 \%$ sobre a biomassa de cada gaiola, fornecidas em comedouros tipo calha, sendo o arraçoamento realizado na forma manual. Ao final de cada biometria ( 28 dias) os peixes foram pesados (g). 
A temperatura da água foi medida diariamente as 9 e 17h. O oxigênio dissolvido foi determinado pelo oxigenômetro modelo Y55. O pH foi determinado por peagâmetro eletrônico modelo F1002. A condutividade foi determinada com o auxílio de um condutivímetro eletrônico. A alcalinidade total foi determinada por titulação com ácido sulfúrico (CARMOUSE, 1994; PARANHOS, 1996). A concentração de amônia foi determinada por colorometria através do método do indofenol, como descrito em Paranhos (1996). O nitrito foi determinado utilizando o método espectrofotométrico clássico baseado na reação de Griess (CARMOUSE, 1994). A determinação do ortofosfato baseou-se na reação entre este e o ácido molíbdico, produzindo ácido fosfomolíbdico. Após redução pelo ácido ascórbico, o composto azul é quantificado por espectrofotometria (CARMOUSE, 1994).

\section{Quanto Maior Melhor (tipo L)}

Foi empregado o tipo de característica funcional de qualidade: "quanto Maior Melhor". Neste caso, o valor ideal é indefinido, não havendo valores nominais especificados, quanto maior for o valor da característica (peso dos peixes), melhor será. Seja A a perda causada por um peixe em ter ultrapassado o limite inferior de tolerância e o seu correspondente desvio $\Delta$. A função perda é expressa por:

$\mathrm{L}(\mathrm{Y})=\mathrm{K}\left[1 / \mathrm{Y}^{2}\right]$ ou $\mathrm{L}(\mathrm{Y})=\mathrm{A} \Delta^{2} \mathrm{v}^{2}($ PHADKE, 1989).

Sejam:

\section{Cálculo do custo de cada peixe}

$\mathrm{P} 1=$ ração + levedura + juvenis + alimentação

$\mathrm{P} 2=$ ração + levedura + juvenis + alimentação

$\ldots=\ldots+\ldots+\ldots+\ldots$

$\mathrm{Pk}=$ ração + levedura + juvenis + alimentação

$\sum_{\substack{1 \\ \text { alimentação }}} \mathrm{P}_{\mathrm{i}}=\sum_{1}^{k}($ ração + levedura + juvenis +
Cálculo de A:

$\mathrm{A}=\sum_{1}^{k} \mathrm{P}_{\mathrm{i}} / \mathrm{k}$ com $\mathrm{i}=1,2, \ldots, \mathrm{k}$

Onde, k é o número de peixes.

A é a perda causada por um peixe em ter ultrapassado o limite inferior de tolerância.

\section{Cálculo de $\Delta:$}

A produção de peixes que apresentar elevada dispersão terá um custo mais alto devido aos descartes e, conseqüentemente maiores perdas da qualidade. Nesse caso, aconselha-se a divisão dos peixes em lotes para o cálculo da tolerância e redução das perdas.

Em geral, procede-se da seguinte forma para o cálculo da tolerância $(\Delta)$ :

$\Delta=\bar{x}-\mathrm{s}$

Onde, $\bar{x}$ é a média e s é o desvio padrão.

Cálculo de $\mathrm{v}^{2}$ :

$\mathrm{v}^{2}=1 / \mathrm{n}\left(1 / \mathrm{y}_{1}^{2}+1 / \mathrm{y}_{2}^{2}+\ldots+1 / \mathrm{y}_{\mathrm{n}}^{2}\right)$, onde,

$\mathrm{V}^{2}$ é o desvio quadrático médio e $\mathrm{y}_{\mathrm{i}}$ é o valor medido para a característica estudada (peso).

\section{Resultados e discussão}

Os valores médios de temperatura $(22,30 \pm$ $\left.1,05^{\circ} \mathrm{C}\right)$; de $\mathrm{pH}(8,09 \pm 0,68)$; de condutividade $(18,46 \pm 3,02 \mu \mathrm{S} / \mathrm{cm})$; de oxigênio dissolvido da água $(4,57 \pm 0,45 \mathrm{mg} / \mathrm{L})$; de alcalinidade $(290,42 \pm$ $\left.55,36 \mathrm{mgCaCO}_{3} / \mathrm{L}\right)$; de amônia $(0,04 \pm 0,01 \mathrm{mg} / \mathrm{L})$ e de nitrito $(0,18 \pm 0,02 \mathrm{mg} / \mathrm{L})$, obtidos durante o período experimental, mantiveram-se dentro da faixa recomendada por Sipaúba-Tavares (1995), não influenciando o desempenho dos peixes.

As leveduras (Saccharomyces Cerevisiae) são microorganismos unicelulares, que se reproduzem assexuadamente por brotamento desenvolvendo-se na fermentação alcoólica. Segundo Yousri (1982), as leveduras, dentre os microorganismos, parecem 
reunir as características mais favoráveis ao uso na alimentação humana e animal.

A levedura apresenta como característica um bom balanceamento de aminoácidos, também se destaca pela grandeza de vitaminas de complexo B, principalmente Tiamina, Riboflavina, Niacina e Ácido Pantatênico. Existe ainda uma quantidade razoável de ergosterol, o que a torna numa excelente fonte de vitamina $\mathrm{D}$.

$\mathrm{Na}$ criação de ruminantes, a alimentação é responsável por grande parte dos custos (60 a 70\%), sejam estes animais confinados ou não. Portanto, é de fundamental importância conhecer as características dos alimentos e seu balanceamento na formulação de rações, as quais devem ser formuladas para suprir as necessidades dos animais, explorando sua máxima capacidade digestiva, de modo a atingir o seu potencial genético para o aproveitamento da ração (MARTINS et al., 2000).

$\mathrm{Na}$ (Tabela 2), encontram-se os resultados médios para o peso das tilápias em função da inclusão de levedura na dieta. Não foram observados efeitos dos tratamentos $(p>0,05)$ sobre a sobrevivência e conversão alimentar, mas houve efeito quadrático sobre o ganho de peso das tilápias ( $\mathrm{Y}=73,39+$ $\left.0.173 \mathrm{X}-0.0034 \mathrm{X} 2 ; \mathrm{R}^{2}=0,9986\right)$, concluindo que o melhor nível de inclusão de levedura como fonte protéica na dieta para juvenis revertidos a partir da tilápia do Nilo é 25,44\%.

O resultado encontrado no presente estudo concorda com os valores encontrados por Ribeiro et al. (1996) que não observou efeito dos tratamentos sobre a sobrevivência e conversão alimentar das tilápias do Nilo.

Para Furuya et al. (2000), trabalhando com níveis crescentes de inclusão de levedura desidratada nos tratamentos $(0,00 ; 7,80 ; 15,60 ; 23,40$ e $31,20 \%)$ na dieta, não observou efeito dos tratamentos sobre a sobrevivência e conversão alimentar, porém observou efeito quadrático sobre o ganho de peso $\left(\mathrm{Y}=1,7133-0,0477 \mathrm{X}-0,0017 \mathrm{X}^{2}, \mathrm{R}^{2}=0,78\right)$, tendo como o melhor nível de inclusão de levedura seca na dieta para alevinos revertidos de tilápias do Nilo de $14 \%$.

A (Tabela 3) apresenta os resultados obtidos para peso final individual do grupo controle $\left(\mathrm{T}_{1}\right)$ e grupos testes $\left(\mathrm{T}_{2}, \mathrm{~T}_{3}\right.$ e $\left.\mathrm{T}_{4}\right)$ das tilápias do Nilo.

Aplicação da Função perda de Taguchi

$\mathrm{Na}$ (Tabela 4) e (Figura 1) estão presentes às perdas de Taguchi nos tratamentos $\mathrm{T}_{1}, \mathrm{~T}_{2}, \mathrm{~T}_{3}$ e $\mathrm{T}_{4}$ para os custos de produção.

Tabela 2. Valores médios para o peso das tilápias (g), em função da inclusão de levedura na ração.

\begin{tabular}{lcccc}
\hline \multicolumn{5}{c}{ Peso $\mathbf{( g})^{*}$} \\
\hline Dias & $\mathbf{T}_{\mathbf{1}} \mathbf{=} \mathbf{0} \%$ & $\mathbf{T}_{\mathbf{2}}=\mathbf{2 0} \%$ & $\mathbf{T}_{\mathbf{3}}=\mathbf{4 0 \%}$ & $\mathbf{T}_{\mathbf{4}}=\mathbf{6 0} \mathbf{6}$ \\
\hline 0 & $37,26 \pm 4,82$ & $37,65 \pm 5,07$ & $37,28 \pm 5,56$ & $36,90 \pm 5,78$ \\
28 & $46,34 \pm 5,72$ & $46,90 \pm 6,73$ & $47,40 \pm 6,12$ & $43,91 \pm 6,59$ \\
56 & $71,90 \pm 6,34$ & $73,56 \pm 7,02$ & $74,50 \pm 7,67$ & $67,90 \pm 7,65$ \\
84 & $95,70 \pm 7,89$ & $98,43 \pm 8,67$ & $96,80 \pm 8,70$ & $93,68 \pm 8,42$ \\
112 & $115,89 \pm 8,93$ & $120,52 \pm 9,51$ & $118,69 \pm 10,45$ & $114,97 \pm 9,48$ \\
\hline \multicolumn{5}{c}{ Dados de consumo } \\
\hline Conversão alimentar & 4,76 & 3,31 & 4,34 & 5,50 \\
Sobrevivência (\%) & 72,22 & 77,78 & 77,78 & 72,22 \\
\hline
\end{tabular}

*Efeito quadrático sobre o ganho de peso $\left(\mathrm{Y}=73,39+0,173 \mathrm{X}-0,0034 \mathrm{X}^{2} ; \mathrm{R}^{2}=0,9986\right)$ 
Tabela 3. Peso final após 112 dias de experimento.

\begin{tabular}{lcccccccccccc}
\hline & \multicolumn{1}{c}{ Bloco 1 } & \multicolumn{1}{c}{ Bloco 2 } & \multicolumn{5}{c}{ Bloco 3 } \\
\hline Rep. & $\mathrm{T}_{1}$ & $\mathrm{~T}_{2}$ & $\mathrm{~T}_{3}$ & $\mathrm{~T}_{4}$ & $\mathrm{~T}_{1}$ & $\mathrm{~T}_{2}$ & $\mathrm{~T}_{3}$ & $\mathrm{~T}_{4}$ & $\mathrm{~T}_{1}$ & $\mathrm{~T}_{2}$ & $\mathrm{~T}_{3}$ & $\mathrm{~T}_{4}$ \\
\hline 1 & 134,0 & 129,0 & 129,0 & 116,6 & 108,0 & 132,0 & 152,0 & 95,0 & 84,0 & 171,7 & 101,0 & 125,0 \\
2 & 114,5 & 120,3 & 136,0 & 109,8 & 119,0 & 157,0 & 142,0 & 125,7 & 147,0 & 135,7 & 163,0 & 60,0 \\
3 & 126,8 & 115,4 & 115,7 & 102,9 & 104,0 & 59,0 & 123,0 & 87,9 & 105,0 & 123,8 & 118,0 & 121,3 \\
4 & 101,6 & 120,5 & 132,0 & 105,8 & 103,0 & 134,8 & 131,0 & 89,8 & 78,0 & 90,0 & 50,0 & 78,4 \\
5 & & & 97,0 & & 98,0 & 99,5 & & & & & 68,0 & 98,6 \\
6 & & & & & & 100,0 & & & & & & \\
\hline
\end{tabular}

Média $(\bar{x})=111,24$ e Desvio-padrão (s) $=26,14$

Tabela 4. Custo de produção nos tratamentos $\mathrm{T}_{1}, \mathrm{~T}_{2}, \mathrm{~T}_{3}$ e $\mathrm{T}_{4}$.

\begin{tabular}{|c|c|c|c|c|c|c|c|c|c|}
\hline \multirow[b]{2}{*}{ Especificação } & \multicolumn{4}{|c|}{ Inclusão de levedura } & \multirow{2}{*}{$\begin{array}{c}\text { Custo } \\
\text { Unitário } \\
(\mathrm{R} \$)\end{array}$} & \multicolumn{4}{|c|}{ Total (R\$) } \\
\hline & $\mathrm{T}_{1}=0 \%$ & $\mathrm{~T}_{2}=20 \%$ & $\mathrm{~T}_{3}=40 \%$ & $\mathrm{~T}_{4}=60 \%$ & & $\mathrm{~T}_{1}=0 \%$ & $\mathrm{~T}_{2}=20 \%$ & $\mathrm{~T}_{3}=40 \%$ & $\mathrm{~T}_{4}=60 \%$ \\
\hline Ração(kg) & 7,62 & 5,36 & 4,06 & 2,36 & 0,90 & 6,86 & 4,82 & 3,65 & 2,12 \\
\hline Levedura(kg) & 0,00 & 1,34 & 2,71 & 3,55 & 0,80 & 0,00 & 1,07 & 2,16 & 2,84 \\
\hline Juvenis & 18 & 18 & 18 & 18 & 0,06 & 1,08 & 1,08 & 1,08 & 1,08 \\
\hline Alimentação(h) & 5,00 & 5,00 & 5,00 & 5,00 & 4,00 & 2,00 & 2,00 & 2,00 & 2,00 \\
\hline Total & $\ldots$ & $\ldots$ & $\ldots$ & $\ldots$ & $\ldots$ & 9,94 & 8,97 & 8,89 & 8,04 \\
\hline
\end{tabular}

a) $\mathrm{T}_{1}=0 \%$ de inclusão de levedura de destilaria

Cálculo de A: $\mathrm{A}=\sum_{1}^{k} \mathrm{P}_{\mathrm{i}} / \mathrm{k}=9,94 / 18=0,55$

Cálculo de $\Delta: \Delta=\frac{1}{x}-\mathrm{s}=109,45-19,05=90,40$

Cálculo de $\mathrm{V}^{2}: \mathrm{v}^{2}=(0,0000909)$

Cálculo da Função Perda de Taguchi (L):

$\mathrm{L}=\mathrm{A} \Delta^{2} \mathrm{v}^{2}=0,55(90,40)^{2}(0,0000909)$

$\mathrm{L}=0,409, \log 0,18 \times 0,409=\mathrm{R} \$ 7,35$.

b) $\mathrm{T}_{2}=20 \%$ de inclusão de levedura de destilaria

Cálculo de A: $\mathrm{A}=\sum_{1}^{k} \mathrm{P}_{\mathrm{i}} / \mathrm{k}=8,97 / 18=0,50$

Cálculo de $\Delta: \Delta=\frac{1}{x}-\mathrm{s}=120,62-28,02=92,60$

Cálculo de $\mathrm{V}^{2}: \mathrm{v}^{2}=0,0000916$

Cálculo da Função Perda de Taguchi (L):

$\mathrm{L}=\mathrm{A} \Delta^{2} \mathrm{v}^{2}=0,50(92,60)^{2}(0,0000916)$

$\mathrm{L}=0,393, \log 0,18 \times 0,393=\mathrm{R} \$ 7,07$. c) $\mathrm{T}_{3}=40 \%$ de inclusão de levedura de destilaria

Cálculo de A: $\mathrm{A}=\sum_{1}^{k} \mathrm{P}_{\mathrm{i}} / \mathrm{k}=8,89 / 18=0,49$

Cálculo de $\Delta: \Delta=\frac{1}{x}-\mathrm{s}=118,41-30,95=87,46$

Cálculo de $\mathrm{V}^{2}: \mathrm{v}^{2}=0,0001072$

Cálculo da Função Perda de Taguchi (L):

$\mathrm{L}=\mathrm{A} \Delta^{2} \mathrm{v}^{2}=0,49(87,46)^{2}(0,0001072)$

$\mathrm{L}=0,40, \log \mathrm{o}, 18 \times 0,40=\mathrm{R} \$ 7,23$.

d) $\mathrm{T}_{4}=60 \%$ de inclusão de levedura de destilaria

Cálculo de $\mathrm{A}: \mathrm{A}=\sum_{1}^{k} \mathrm{P}_{\mathrm{i}} / \mathrm{k}=8,04 / 18=0,45$

Cálculo de $\Delta: \Delta=\frac{1}{x}-\mathrm{s}=101,29-19,31=81,98$

Cálculo de V를 $\mathrm{v}^{2}=0,0001111$

Cálculo da Função Perda de Taguchi (L):

$\mathrm{L}=\mathrm{A} \Delta^{2} \mathrm{v}^{2}=0,45(81,98)^{2}(0,0001111)$

$\mathrm{L}=0,34, \log 0,18 \times 0,34=\mathrm{R} \$ 6,05$. 


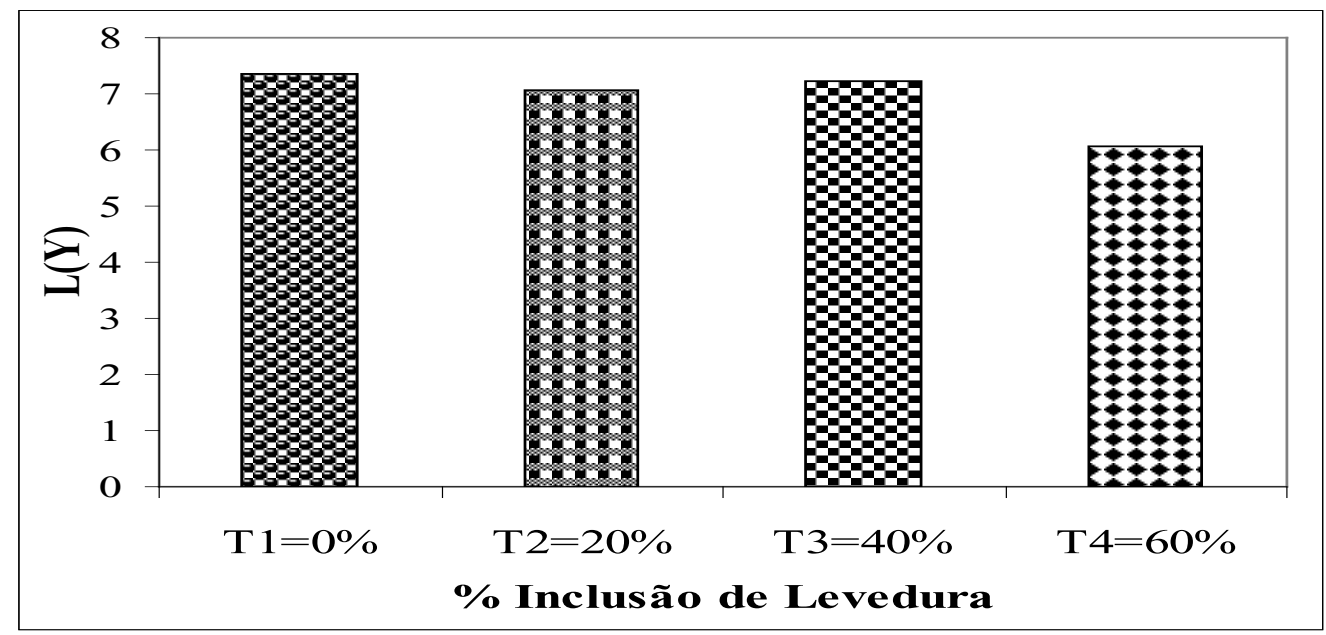

Figura 1. Perdas de Taguchi para os custos de produção

As perdas de Taguchi para o custo de produção nas gaiolas nos tratamentos $\mathrm{T}_{2}=20 \%, \mathrm{~T}_{3}=40 \%$ e $\mathrm{T}_{4}$ $=60 \%$ (testes) foram menores que o grupo controle $\left(\mathrm{T}_{1}=0 \%\right)$. O resultado encontrado no presente estudo concorda com os valores encontrados por
Medri et al. (2004), confirmando o direcionamento da inclusão levedura de destilaria em substituição a ração de origem tradicional.

$\mathrm{Na}$ (Tabela 5) e (Figura 2) estão presentes as perdas de Taguchi nos tratamentos $\mathrm{T}_{1}, \mathrm{~T}_{2}, \mathrm{~T}_{3}$ e $\mathrm{T}_{4}$ para os peixes mortos.

Tabela 5. Peixes mortos nos tratamentos $T_{1}, T_{2}, T_{3}$ e $T_{4}$.

\begin{tabular}{lcccc|c|cccc}
\hline & \multicolumn{3}{c|}{ Inclusão de levedura } & $\begin{array}{c}\text { Custo } \\
\text { Unitário }\end{array}$ & \multicolumn{4}{c}{ Total (R\$) } \\
Especificação & $\mathrm{T}_{1}=0 \%$ & $\mathrm{~T}_{2}=20 \%$ & $\mathrm{~T}_{3}=40 \%$ & $\mathrm{~T}_{4}=60 \%$ & $(\mathrm{R} \$)$ & $\mathrm{T}_{1}=0 \%$ & $\mathrm{~T}_{2}=20 \%$ & $\mathrm{~T}_{3}=40 \%$ & $\mathrm{~T}_{4}=60 \%$ \\
Ração(kg) & 0,62 & 0,46 & 0,36 & 0,22 & 0,90 & 0,56 & 0,41 & 0,32 & 0,20 \\
Levedura(kg) & 0.00 & 0,11 & 0,23 & 0,33 & 0,80 & 0,00 & 0,09 & 0,18 & 0,26 \\
Juvenis & 5 & 4 & 4 & 5 & 0,06 & 0,30 & 0,24 & 0,24 & 0,30 \\
Alimentação(h) & 1,11 & 0,89 & 0,89 & 1,11 & 4,00 & 4,44 & 3,56 & 3,56 & 4,44 \\
Total & $\ldots$ & $\ldots$ & $\ldots$ & $\ldots$ & $\ldots$ & 5,30 & 4,30 & 4,30 & 5,20 \\
\hline
\end{tabular}

a) $\mathrm{T}_{1}=0 \%$ de inclusão de levedura de destilaria Cálculo de $\mathrm{A}: \mathrm{A}=\sum_{1}^{k} \mathrm{P}_{\mathrm{i}} / \mathrm{k}=5,30 / 5=1,06$

Cálculo de $\Delta: \Delta=\bar{x}-\mathrm{s}=109,45-19,05=90,40$

Cálculo de V를 $: \mathrm{v}^{2}=(0,0000909)$

Cálculo da Função Perda de Taguchi (L):

$\mathrm{L}=\mathrm{A} \Delta^{2} \mathrm{v}^{2}=1,06(90,40)^{2}(0,0000909)$

$\mathrm{L}=0,787 \operatorname{logo}, 5 \times 0,787=\mathrm{R} \$ 3,94$. b) $\mathrm{T}_{1}=20 \%$ de inclusão de levedura de destilaria

Cálculo de A: $\mathrm{A}=\sum_{1}^{k} \mathrm{P}_{\mathrm{i}} / \mathrm{k}=4,30 / 4=1,08$

Cálculo de $\Delta: \Delta=\bar{x}-\mathrm{s}=120,62-28,02=92,60$

Cálculo de V를 $\mathrm{v}^{2}=0,0000916$

Cálculo da Função Perda de Taguchi (L):

$\mathrm{L}=\mathrm{A} \Delta^{2} \mathrm{v}^{2}=1,08(92,60)^{2}(0,0000916)$

$\mathrm{L}=0,848, \log 0,4 \times 0,848=\mathrm{R} \$ 3,39$. 
c) $\mathrm{T}_{3}=40 \%$ de inclusão de levedura de destilaria

Cálculo de A: $\mathrm{A}=\sum_{1}^{k} \mathrm{P}_{\mathrm{i}} / \mathrm{k}=4,30 / 4=1,08$

Cálculo de $\Delta: \Delta=\frac{1}{x}-\mathrm{s}=118,41-30,95=87,46$

Cálculo de $\mathrm{V}^{2}: \mathrm{v}^{2}=0,0001072$

Cálculo da Função Perda de Taguchi (L):

$\mathrm{L}=\mathrm{A} \Delta^{2} \mathrm{v}^{2}=1,08(87,46)^{2}(0,0001072)$

$\mathrm{L}=0,886, \log 0,4 \times 0,886=\mathrm{R} \$ 3,54$.

d) $\mathrm{T}_{4}=60 \%$ de inclusão de levedura de destilaria Cálculo de A: $\mathrm{A}=\sum_{1}^{k} \mathrm{P}_{\mathrm{i}} / \mathrm{k}=5,20 / 5=1,04$

Cálculo de $\Delta: \Delta=\bar{x}-\mathrm{S}=101,29-19,31=81,98$

Cálculo de V롤 $\mathrm{V}^{2}=0,0001111$
Cálculo da Função Perda de Taguchi (L):

$\mathrm{L}=\mathrm{A} \Delta^{2} \mathrm{v}^{2}=1,04(81,98)^{2}(0,0001111)$

$\mathrm{L}=0,777, \log 0,5 \times 0,777=\mathrm{R} \$ 3,88$.

Perdas de Taguchi para os peixes mortos nas gaiolas nos tratamentos $\mathrm{T}_{2}=20 \%, \mathrm{~T}_{3}=40 \%$ e $\mathrm{T}_{4}=$ $60 \%$ (testes) foram menores que o grupo controle $\left(\mathrm{T}_{1}=0 \%\right)$. O resultado encontrado no presente estudo concorda com os valores encontrados por Medri et al. (2004), confirmando o direcionamento da inclusão levedura de destilaria em substituição a ração de origem tradicional.

$\mathrm{Na}$ (Tabela 6) e (Figura 3) estão presentes as perdas de Taguchi nos tratamentos $\mathrm{T}_{1}, \mathrm{~T}_{2}, \mathrm{~T}_{3}$ e $\mathrm{T}_{4}$ para os peixes descartados.

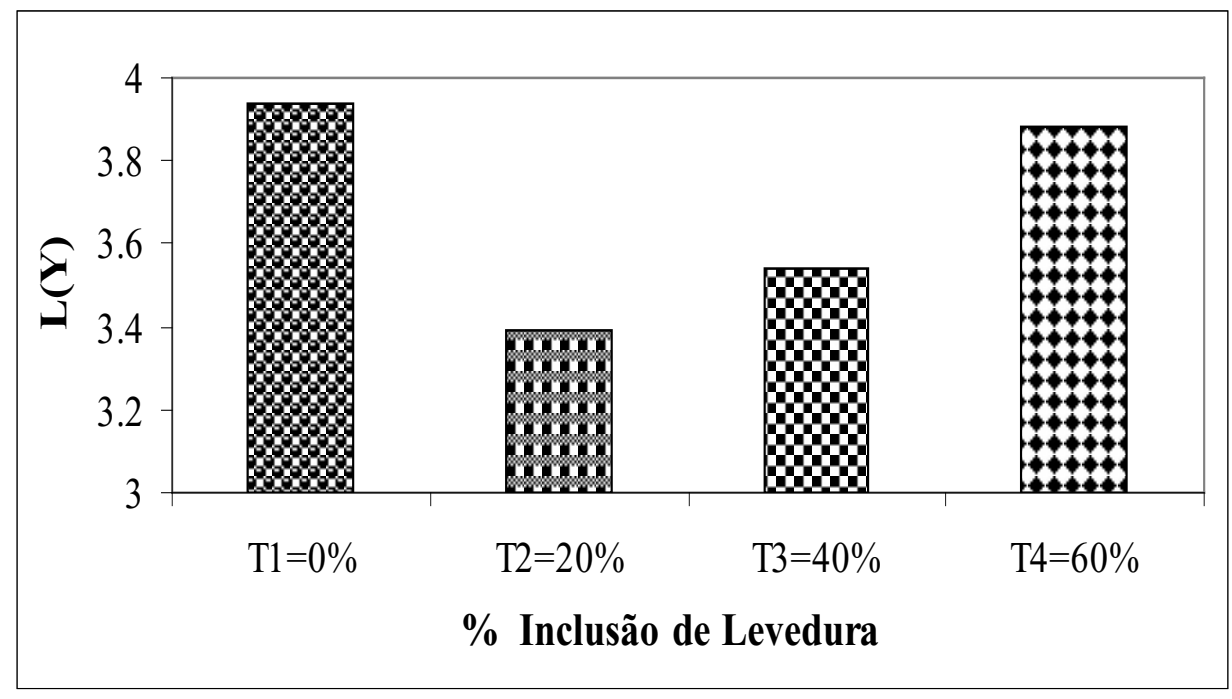

Figura 2. Perdas de Taguchi para os peixes mortos.

Tabela 6. Peixes descartados nos tratamentos $\mathrm{T}_{1}, \mathrm{~T}_{2}, \mathrm{~T}_{3}$ e $\mathrm{T}_{4}$.

\begin{tabular}{|c|c|c|c|c|c|c|c|c|c|}
\hline \multirow[b]{2}{*}{ Especificação } & \multicolumn{4}{|c|}{ Inclusão de levedura } & \multirow{2}{*}{$\begin{array}{c}\text { Custo } \\
\text { Unitário } \\
\text { cost }(\mathrm{R} \$)\end{array}$} & \multicolumn{4}{|c|}{ Total (R\$) } \\
\hline & $\mathrm{T}_{1}=0 \%$ & $\mathrm{~T}_{2}=20 \%$ & $\mathrm{~T}_{3}=40 \%$ & $\mathrm{~T}_{4}=60 \%$ & & $\mathrm{~T}_{1}=0 \%$ & $\mathrm{~T}_{2}=20 \%$ & $\mathrm{~T}_{3}=40 \%$ & $\mathrm{~T}_{4}=60 \%$ \\
\hline Ração(kg) & 0,85 & 0,59 & 0,45 & 0,26 & 0,90 & 0,77 & 0,53 & 0,41 & 0,23 \\
\hline Levedura(kg) & 0.00 & 0,15 & 0,30 & 0,40 & 0,80 & 0,00 & 0,12 & 0,24 & 0,32 \\
\hline Juvenis & 2 & 2 & 2 & 2 & 0,06 & 0,12 & 0,12 & 0,12 & 0,12 \\
\hline Alimentação(h) & 0,44 & 0,44 & 0,44 & 0,44 & 4,00 & 0,88 & 0,88 & 0,88 & 0,88 \\
\hline Total & $\ldots$ & $\ldots$ & $\ldots$ & $\ldots$ & $\ldots$ & 1,77 & 1,65 & 1,65 & 1,55 \\
\hline
\end{tabular}


a) $\mathrm{T}_{1}=0 \%$ de inclusão de levedura de destilaria

Cálculo de $\mathrm{A}: \mathrm{A}=\sum_{1}^{k} \mathrm{P}_{\mathrm{i}} / \mathrm{k}=1,77 / 2=0,89$

Cálculo de $\Delta: \Delta=\frac{1}{x}-\mathrm{s}=109,45-19,05=90,40$

Cálculo de V를 $: \mathrm{v}^{2}=(0,0000909)$

Cálculo da Função Perda de Taguchi (L):

$\mathrm{L}=\mathrm{A} \Delta^{2} \mathrm{v}^{2}=0,89(90,40)^{2}(0,0000909)$

$\mathrm{L}=0,661 \operatorname{logo}, 2 \times 0,661=\mathrm{R} \$ 1,32$.

b) $\mathrm{T}_{1}=20 \%$ de inclusão de levedura de destilaria

Cálculo de A: $\mathrm{A}=\sum_{1}^{k} \mathrm{P}_{\mathrm{i}} / \mathrm{k}=1,65 / 2=0,83$

Cálculo de $\Delta: \Delta=\frac{1}{x}-\mathrm{s}=120,62-28,02=92,60$

Cálculo de V를 $\mathrm{V}^{2}=0,0000916$

Cálculo da Função Perda de Taguchi (L):

$\mathrm{L}=\mathrm{A} \Delta^{2} \mathrm{v}^{2}=0,83(92,60)^{2}(0,0000916)$

$\mathrm{L}=0,652, \log 0,2 \times 0,652=\mathrm{R} \$ 1,30$.

c) $\mathrm{T}_{3}=40 \%$ de inclusão de levedura de destilaria

Cálculo de $\mathrm{A}: \mathrm{A}=\sum_{1}^{k} \mathrm{P}_{\mathrm{i}} / \mathrm{k}=1,65 / 2=0,83$

Cálculo de $\Delta: \Delta=\frac{1}{x}-\mathrm{s}=118,41-30,95=87,46$
Cálculo de V르: $\mathrm{v}^{2}=0,0001072$

Cálculo da Função Perda de Taguchi (L):

$\mathrm{L}=\mathrm{A} \Delta^{2} \mathrm{v}^{2}=0,83(87,46)^{2}(0,0001072)$

$\mathrm{L}=0,681, \log 0,2 \times 0,681=\mathrm{R} \$ 1,36$.

d) $\mathrm{T}_{4}=60 \%$ de inclusão de levedura de destilaria

Cálculo de A: $\mathrm{A}=\sum_{1}^{k} \mathrm{P}_{\mathrm{i}} / \mathrm{k}=1,55 / 2=0,78$

Cálculo de $\Delta: \Delta=\bar{x}-\mathrm{s}=101,29-19,31=81,98$

Cálculo de V를 $: \mathrm{v}^{2}=0,0001111$

Cálculo da Função Perda de Taguchi (L):

$\mathrm{L}=\mathrm{A} \Delta^{2} \mathrm{v}^{2}=0,78(81,98)^{2}(0,0001111)$

$\mathrm{L}=0,582, \log 0,2 \times 0,582=\mathrm{R} \$ 1,16$.

$\mathrm{Na}$ Figura 3 as perdas para os peixes descartados foram $\mathrm{R} \$ 1,32,1,30,1,36$ e 1,16 para os respectivos tratamentos $\mathrm{T}_{1}=0 \%, \mathrm{~T}_{2}=20 \%, \mathrm{~T}_{3}=40 \%$ e $\mathrm{T}_{4}=60 \%$ de proteína de levedura de destilaria em substituição a proteína de fontes tradicionais. As perdas para o tratamento $\mathrm{T}_{3}$ foram maiores que os outros tratamentos. As perdas nos tratamentos $\mathrm{T}_{2}$ e $\mathrm{T}_{4}$ foram menores do que o grupo controle $\left(\mathrm{T}_{1}=0 \%\right)$.

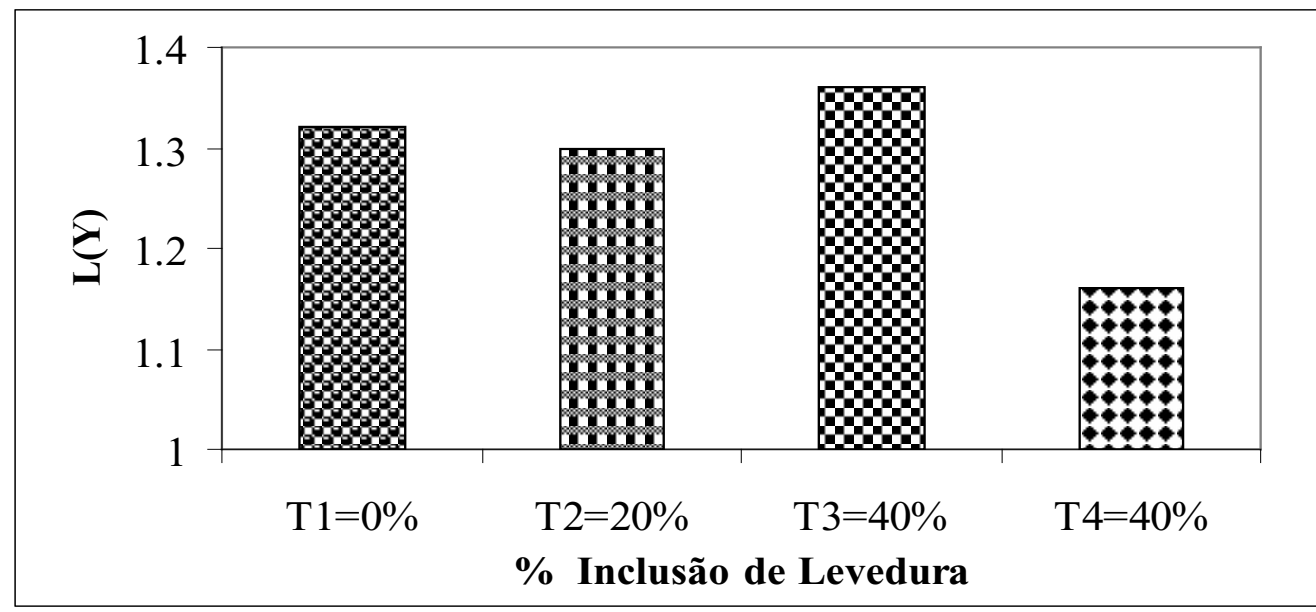

Figura 3. Perdas de Taguchi para os peixes descartados. 


\section{Conclusões}

A análise de variância foi aplicada mostrando que não houve diferenças estatísticas $(p>0,05)$ entre os efeitos dos tratamentos sobre a sobrevivência e conversão alimentar, mas houve efeito quadrático sobre o ganho de peso das tilápias $(\mathrm{Y}=73,39+$ $\left.0.173 \mathrm{X}-0.0034 \mathrm{X} 2 ; \mathrm{R}^{2}=0,9986\right)$, concluindo que o melhor nível de inclusão de levedura como fonte protéica na dieta para juvenis revertidos é de 25,44\%. As perdas de Taguchi para os custos de produção e para os peixes mortos nos tratamentos $\mathrm{T}_{2}$ $=20 \%, \mathrm{~T}_{3}=40 \%$ e $\mathrm{T}_{4}=60 \%$ foram menores que o grupo controle $\left(\mathrm{T}_{1}=0 \%\right)$. Este resultado confirma o direcionamento da inclusão de levedura de destilaria em substituição a ração de origem tradicional.

\section{Referências}

ALCESTE, C. C.; JORY, D. E. World tilapia farming: 2001. Aquaculture Magazine, [S.1.]: p. 40-52. Buyer's Guide \& Industry Directory, 2002.

ALCOPAR. Sub-produtos: na indústria sucro-alcooleira nada se perde, tudo se transforma. Relatório do Setor sucro-alcooleira. [S.1.]: p. 13-18, 1992.

ALVES, L. M. C. G.; PEZZATO, L. E.; NETO, A. C. G.; PEZZATO, A. C.; BARROS, M. M.; PADOVANI, C. Avaliação de níveis crescentes de levedura seca de vinhaça incorporadas às rações de Tilápia do Nilo. In: SIMPÓSIO LATINOAMERICANO DE AQÜICULTURA, 6. SIMPÓSIOS BRASILEIROS DE AQÜICULTURA, 5., 1988, Florianópolis, Resumos... Florianópolis: Abraq, 1988, p. 355-361.

BOSCOLO, V. R.; HAYASHI, C.; BOSCOLO, W. R.; FARIA, A. C. E. A.; SOARES, C. M.; MEURER, F. Desempenho e características de carcaça de machos revertidos de tilápias do Nilo (Oreochromis niloticus), Linhagens Tailandesa e Comum, nas Fases Inicial e de Crescimento. Rev. Bras. Zootec.,Viçosa, v. 30, n. 5, p. 1391-1396, 2001.

BOZANO, L.; ROMERO S. Criação de tilápia em gaiolas. Wokshop Internacional de tilápia, cultivo y Desarrollo Pesquero. Tarapoto, San Martin, Peru. p. 1213, July, 2001.

CARMOUSE, G. P. Metabolismo dos ecossistemas aquáticos: fundamentos teóricos, métodos de estudo e análise química. São Paulo: Edgard Brucher: Fapesp, 1994.
CYRINO, J. E. P.; CARNEIRO, P. C. F.; BOZANO, G. L. N.; CASEIRO, A. C. Desenvolvimento da criação de peixes em tanques-rede. In: AQÜICULTURA BRASIL 98. 1998, Recife. Anais... Recife: ABRAq, World Aquaculture, ABCC, p .409-433. v. 1.

DEMING, W. E. A nova economia. Rio de Janeiro: Qualitymark, 1997.

FURUYA, W. M.; SERON, S.; VARGAS, L.; HAYASHI, C.; FURUYA, V. R. B.; SOARES, C. M. Níveis de levedura "spray-dried" na dieta de alevinos revertidos de tilápia do Nilo (Oreochromis niloticus L.). Ciência Rural, Santa Maria, v. 30, n. 4, p. 699-704, 2000.

GUEDES, T. A. Procedimentos de otimização no planejamento e controle da qualidade de produtos $e$ processos. Florianópolis, 1996. Tese (Doutorado em Engenharia de Produção). Universidade Federal de Santa Catarina, Florianópolis, 1996.

HAYASHI, C. Breves considerações sobre as tilápias. In: RIBEIRO, R. P., HAYASHI, C., FURUYA, W. M. (Ed.). Curso de piscicultura-criação racional de tilápias. Maringá: FADEC/UEM, 1995, p. 4.

KACKAR, R. N. Taguchi's quality philosophy: analysis and commentary. Quality progress. New York, v. 19, n. 12, p. 19-29, 1986.

LAHAV, E., RA'NAN, Z. Salinity tolerance of genetically produced tilápia (Oreochromis) hybrids. Isr. J. Aquac., Bamidgeh, v. 49, n. 3, p. 160-165, 1997.

LITCHFIELD, J. H. Single-ceel Proteins. Science. [S.1.]: v. 219, p. 740-746, 1983.

LOVSHIN, L. L. Tilápia farming: a growing worldwide aquaculture industry. In: SIMPÓSIO SOBRE MANEJO E NUTRIÇÃO DE PEIXES, 1., 1997, Piracicaba. Anais... Piracicaba: CBNA, 1997. p. 137-164.

MACINTOSCH, D. J.; LITTLE, D. C. Nile tilápia (Oreochromis niloticus). In: BROMAGE, N. R.; ROBERTS, R. J. (Ed.). Roodstock management and egg and larval quality. London: Blackwell Science, cap. 12, p. 277-320, 1995.

MARTINS, A. S.; PRADO, I. N.; ZEOULA, L. M.; BRANCO, A. F.; NASCIMENTO, W. G. Digestibilidade aparente de dietas contendo milho ou casca de mandioca e farelo de algodão ou levedura como fonte protéica em novilhas. Revista Brasileira de Zootecnia, Maringá, v. 29, n. 1, p. 269-277, 2000.

MATTOS, W.R. S.; DANTAS D’ARCE, R.; MACHADO, P. F. O uso de levedura da fermentação alcoólica na alimentação de ruminantes. Informe Agropecuário, Belo Horizonte, v. 10, n. 119, p. 56-60, 1984. 
MEDRI, V.; MEDRI, W.; DALMAS, J. C.; CAETANOFILHO, M. Taguchi's Loss Function Applied in the Breending of Tilapia, Oreochromis niloticus Fed With Different Levels of Proteins of Yeast in Tank-Nets. Arquivos de Ciências Veterinárias e Zoologia da Unipar, Umuarama, v. 7, n. 2, p. 115-121, 2004.

PARANHOS, R. Alguns métodos para análise da água. Rio de Janeiro: UFRJ, sub-reitoria e ensino de graduação e corpos discente/SR - 1. 1996. 200p. (Cadernos Didáticos UFRJ, n. 19)

PEREIRA-DA-SILVA, E. M.; PEZZATO, L. E. Respostas da tilápia do Nilo (Oreochromis niloticus) à atratividade e palatabilidade de ingredientes utilizados na alimentação de peixes. Revista Brasileira de Zootecnia. Viçosa, v. 29, n. 5, p. 1273-1280, 2000.

PHADKE, M. S. Quality engineering using robust design. Englewood Cliffs: PTR Prentice Hall, p. 18-22, 1989.

POPMA, T. J.; PHELPS, R. P. Status report to commercial tilápia producers on monose $\mathrm{x}$ fingerling productions techniques. In: AQUICULTURA BRASIL'98, 1998, Recife. Anais... Recife: SIMBRAQ, 1998. p. 127-145.

POPMA, T. J.; GREEN, B.W. Aquacultural production manual: Sex reversal of tilapia in earthen ponds. Auburn: Auburn University, International Center for Aquaculture, 1990. 15p. (Research and Development Series, n. 35).
RIBEIRO, R.P.;HAYASHI,C.;FURUYA,W.M.;FURYA, V. R. B.; SOARES, C. M. Utilização de diferentes níveis de levedura seca, Saccharomyces cerevisiae, em dietas para alevino de tilápias do nilo, Oreochomis niloticus, em cultivo monossexo. In: SIMPÓSIO BRASILEIRO DE AQÜICULTURA, 9., 1996, Sete Lagoas. Resumos... Sete Lagoas, Simbraq. 1996. p. 99.

ROSS, P. J. Aplicações das técnicas de taguchi na engenharia da qualidade. São Paulo: McGraw-Hill, 1991.

SIPAÚBA-TAVARES, V. L. S. Limnologia aplicada à aqüicultura. Jaboticabal: FUNEP. 1995. 70p.

STANGE, P. Sobre o gerenciamento da produção orientado para a qualidade total da empresa com base na função perda de Taguchi. Florianópolis: EPS/UFSC, 1996.

TAGUCHI, G.; ELSAYED, E. A.; HSIANG, T. C. Engenharia da qualidade em sistemas de produção. São Paulo: Mc Graw - Hill, 1990. 235p

TAGUCHI, G.; TAGUCHI, S.; CHOWDHURY, S. Robust engineering. New York: McGraw-Hill, 1999.

YOUSRI, R. F. Single cell protein: its potential use for animal and human nutrition. World Animal Review and Animal Production, Rome, v. 18, n. 23, p. 46-67, 1982. 